\title{
Bacteriological Analysis of Indoor Air of Three Hospitals in Lahore, Pakistan
}

\author{
Memoona Ishtiaq ${ }^{1}$, Irfan Anjum² ${ }^{2 *}$, Muhammad ljaz ${ }^{1}$ \\ ${ }^{1}$ The University of Lahore, Faculty of Pharmacy, Lahore, Pakistan. \\ ${ }^{2}$ Hacettepe University, Faculty of Pharmacy, Department of Pharmacology, 06100 Sıhhiye, Ankara, Turkey.
}

\begin{abstract}
The aim of present study was to determine the quality of indoor air of different wards of three hospitals in Lahore to check the atmosphere of these hospitals might be a potential source of hospital acquired infections. Using Buck's biological air sampler, microbiological samples were collected from different units of three hospitals. The average amount of microbial loads was determined by using colony counter (Suntex, CC-570). The present study showed that bacterial population was increased in Out Patient Department (75.89\%), Intensive Care Unit (78.43\%) and Nursery Unit (81.5\%) statistically significant in three hospitals at evening time. The bacteria isolates were Pseudomonas aeruginosa, Staphylococcus aureus, Klebsiella pneumonia and Escherichia coli. It was found that indoor air quality of the three hospitals varied depending on disinfection process frequency and number of individuals present in environment. The average number of microorganisms in the atmosphere of hospitals did not fulfill the maximum allowed colony forming units per cubic meter.
\end{abstract}

Keywords: Hospital acquired infection; indoor air; microbial load

\section{INTRODUCTION}

One of the primary goal of a hospital is control of infection spread. However sometimes when a patient goes to hospital for the treatment of some other condition, he acquires an infection during his stay at hospital, referred as hospital acquired infection (HAI). HAI is also known as nosocomial infection. A great attention has been focused on HAIs and their control strategies because of increase number of nosocomial infections over the past decade. ${ }^{1}$ The result of HAI may range from longer hospital stays to development of a condition that needs sur-

*Corresponding author: Irfan Anjum

E-mail address: anjuum95@yahoo.com 
gery or even to death. ${ }^{2}$ Hence, HAIs elevate morbidity, mortality and treatment costs. ${ }^{3}$ HAIs occurrence takes place worldwide and affecting the population of developing as well as developed countries. ${ }^{4}$ According to a study conducted by World Health Organization (WHO), in 55 hospitals of 14 countries representing four WHO regions (Europe, Eastern Mediterranean, South-East Asia and Western Pacific) an average of 8.7\% of hospital patients had acquired nosocomial infection. Another study showed that there was 9.1\% (Greece), 7\% (Spain), 5.1\% (Norway) and 4.6\% (Slovenia) annually HAIs prevalence. ${ }^{5-7}$

Various factors including air, surfaces, hands, water and a number of routes such as oral, intravenous or surgery may be involved in spread of HAIs. Indoor patients are more prone to HAIs because of their underlying disease conditions. ${ }^{8}$ Transmission of microorganisms that cause HAIs usually takes place through hands of physicians, nurses and other paramedical staff in intensive care unit (ICU). ${ }^{9}$ Viruses and fungi can cause HAIs but bacteria are the main causative agents involved in nosocomial infections..$^{10}$ The bacteria that are most commonly involved in HAIs include Streptococcus spp., Acinetobacter spp., Enterococci, Pseudomonas aeruginosa (P. aeruginosa), coagulase-negative Staphylococci, Staphylococcus aureus, Bacillus cereus (B. cereus), Legionella and Enterobacteriaceae family members including Proteus mirabilis, Klebsiella pneumonia, Escherichia coli (E. coli), Serratia marcescens. Out of Enterococci, P. aeruginosa, S. aureus and E. coli have a major role. ${ }^{11}$

HAIs and types of causative agents may vary with in different sections of the same hospital or from hospital to hospital. ${ }^{4}$ Generally, nursery department has more frequent and more severe HAIs as newborn infants are more susceptible to infections and another cause may be their prolong hospital stay. ${ }^{12}$ Outpatient department (OPD) may also be a source of HAIs especially for the patients undergoing intravenous treatment. ${ }^{13}$

HAIs are becoming increasingly more important in Pakistan. Therefore, the objectives of present study was to determine the average amount of microorganism loads in the atmosphere of three hospitals at Lahore, Pakistan in order to show that whether the atmosphere of these hospitals might be a potential source of HAIs caused by various microbial pathogens.

\section{METHODOLOGY}

\section{Sample Location}

One hundred and sixty two air samples were collected from outpatient department, intensive care unit and nursery sections of hospital 1, hospital 2 and hospital 3 in Lahore, Pakistan. 


\section{Media Preparation}

According to manufacturer's instructions, tryptic soy agar (TSA) media were prepared. Prepared media was autoclaved at $125^{\circ} \mathrm{C}$ for 15 minutes. After autoclaving, placed it in water bath at $45^{\circ} \mathrm{C}$. When its temperature reached at $45^{\circ} \mathrm{C}$, transferred the media into petri dishes under laminar flow hood (LFH). Before the preparation of media plates, transferred the media bottles and petri dishes in class "A" area under LFH for 15 min. 15-20 ml media had been poured into each petri dish and allowed to solidify. After 15 min removed the plates from LFH and incubated them in incubator for 24 hours at $35^{\circ} \mathrm{C}$. Next day, if there was any growth on media plates, those were discarded and not used for research's purposes.

\section{Air Sampling}

Buck's biological air sampler was used for air sampling. Biological air sampler was sterilized at $180^{\circ} \mathrm{C}$ for 48 hours in hot air oven. Wrapped with sterilized aluminum paper biological air sampler and petri dishes were carried to the sampling places. Placed the petri dish in cavity of air sampler, closed its perforated lid, pressed ON button, and adjusted the air suction time for $10 \mathrm{~min}$ (100L/ mint). After 10 min placed the glass lid on petri dish and wrapped it again with sterilized aluminum foil. For second air sampling, the stainless steel perforated lid was mopped with 70\% isopropyl alcohol and placed on flame for sterilization purpose. Repeated the same procedure. This procedure was performed for taking air sample at 9 am and 5 pm for 3 times from June 2013 to August 2013, once in every month. Samples were carried to Microbiology section of Medisave Pharmaceuticals, Lahore where analysis was done. After that, petri dishes were incubated in hot air incubator at $32-35^{\circ} \mathrm{C}$ for 24 hours. Control petri dishes were not exposed to air but were placed there for $10 \mathrm{~min}$ and same procedure was performed. On next day, plates were studied for colony forming unit count under colony counter (Suntex, CC-570 ) and a number of tests (Gram Staining test, Eosin methylene blue agar test for $E$. coli, Mannitol salt agar test for $S$. aureus, Catalase test for $E$. coli, Klebsiella and $S$. aureus, IMVIC test for $E$. coli and Klebsiella, Vogues-Proskauer test for E. coli and Klebsiella, Simmons's citrate test for $E$. coli and Coagulase test for $S$. aureus) were performed to isolate and identify microorganisms. ${ }^{14}$ Colony forming units per cubic meter $\left(\mathrm{cfu} / \mathrm{m}^{3}\right)$ were calculated by using following formula;

$$
\frac{\text { Colony count in the petri dish }(\mathrm{cfu}) \times 1000}{\text { Aspirated air }(\mathrm{L})}=\mathrm{cfu} / \mathrm{m}^{3}
$$




\section{Statistical Analysis}

Data was analyzed by mean, standard deviation and standard error of the mean. Statistical analysis was done by Student's t test and p $<0.05$ was accepted as significant. Graph Pad Prism 5 was used for analysis.

\section{RESULTS}

\section{Out Patient Department}

Our studies showed that number of colonies of microorganisms at evening time had been increased significantly as compared to those of morning time in OPD of all three hospitals. Control group had zero number of colonies and taken as reference.

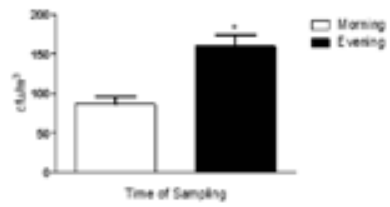

b

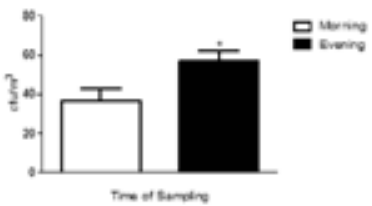

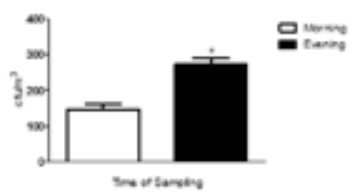

Figure 1. The number of colonies forming units per cubic meter (cfu/m3) at morning at OPD department of (a) hospital 1 (86.78 \pm 9.131$)$, (b) hospital 2 (36.78 \pm 6.112 ) and (c) hospital 3 (146.8 \pm 13.93$)$. At evening hospital 1 (159.5 \pm 13.99$)$, (b) hospital $2(56.78 \pm 5.408)$ and (c) hospital $3(273.8 \pm 14.72)$. ( ${ }^{*} p<0.05$ compared to morning group; $\left.n=9\right)$. (Morning at 9am, Evening at $5 \mathrm{pm})$.

\section{Intensive Care Unit Department}

It had been found that no. of colonies increased at evening time samples as compared to those which were exposed at morning soon after disinfection process in ICU department of three hospitals. Unexposed petri dishes had been taken as reference having no single colony.

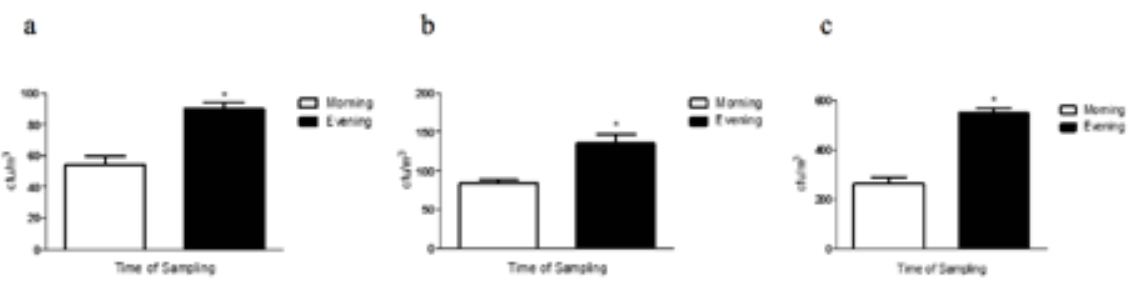

Figure 2. The number of colonies forming units per cubic meter (cfu/m3) at morning at ICU department of (a) hospital 1 (54.44 \pm 4.894$)$, (b) hospital $2(84.11 \pm 3.557)$ and (c) hospital $3(262.0 \pm 27.49)$. At evening hospital $1(90.11 \pm 4.050)$, (b) hospital $2(135.1 \pm 12.05)$ and (c) hospital 3 (548.6 \pm 20.78$)$. ( ${ }^{*} p<0.05$ compared to morning group; $n=9$ ). (Morning at 9am, Evening at $5 \mathrm{pm})$. 


\section{Nursery Department}

Petri dishes exposed for air sampling at evening time at nursery department have increased number of colonies formation when compared with petri dishes exposed at morning time at hospitals. Control unexposed petri dishes had no formation of colonies after 24 hour incubation.
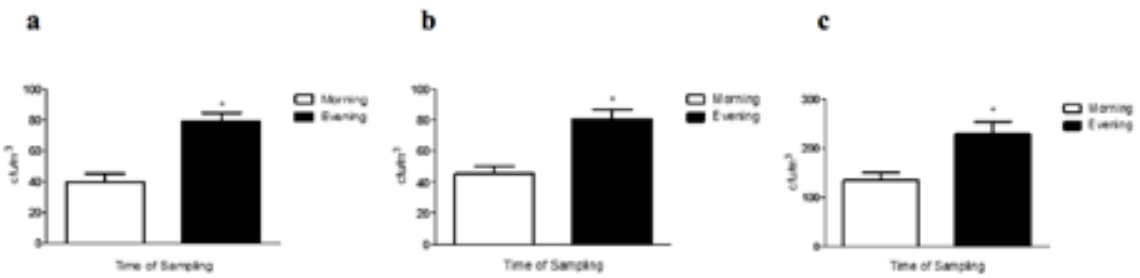

Figure 3. The number of colonies forming units per cubic meter (cfu/m3) at morning at nursery department of (a) hospital 1 (39.89 \pm 5.561$)$, (b) hospital $2(45.44 \pm 4.790)$ and (c) hospital 3 (134.8 \pm 15.02 ). At evening (a) hospital 1 (78.89 \pm 5.675$)$, (b) hospital 2 (80.67 $\pm 6.245)$ and (c) hospital $3(228.1 \pm 25.86)$. ( ${ }^{*} p<0.05$ compared to morning group; $\left.n=9\right)$. (Morning at 9am, Evening at $5 \mathrm{pm}$ ).

Table 1. Number of live microorganisms in air samples collected from OPD at morning and evening in Hospital 1, Hospital 2 and Hospital $3(n=3)$.

\begin{tabular}{|c|c|c|c|c|c|c|c|c|c|c|c|c|}
\hline \multirow{3}{*}{ Samples } & \multicolumn{4}{|c|}{ Hospital 1} & \multicolumn{4}{|c|}{ Hospital 2} & \multicolumn{4}{|c|}{ Hospital 3} \\
\hline & \multicolumn{2}{|c|}{ Morning } & \multicolumn{2}{|c|}{ Evening } & \multicolumn{2}{|c|}{ Morning } & \multicolumn{2}{|c|}{ Evening } & \multicolumn{2}{|c|}{ Morning } & \multicolumn{2}{|c|}{ Evening } \\
\hline & $\begin{array}{c}\text { Avg } \\
\left(\mathrm{cfu} / \mathrm{m}^{3}\right)\end{array}$ & SD & $\begin{array}{c}\text { Avg } \\
\left(\mathrm{cfu} / \mathrm{m}^{3}\right)\end{array}$ & SD & \begin{tabular}{c|} 
Avg \\
$\left(\mathrm{cfu} / \mathrm{m}^{3}\right)$
\end{tabular} & SD & $\begin{array}{c}\text { Avg } \\
\left(\mathrm{cfu} / \mathrm{m}^{3}\right)\end{array}$ & SD & $\begin{array}{c}\text { Avg } \\
\left(\mathrm{cfu} / \mathrm{m}^{3}\right)\end{array}$ & SD & \begin{tabular}{c|} 
Avg \\
$\left(\mathrm{cfu} / \mathrm{m}^{3}\right)$
\end{tabular} & SD \\
\hline $1^{\text {st }}$ month & 86.66 & 26.1 & 182 & 25.23 & 54.33 & 16 & 67 & 23 & 168.33 & 44.37 & 260.33 & 46.37 \\
\hline $2^{\text {nd }}$ month & 80.66 & 17.5 & 160 & 53.67 & 35.33 & 11.93 & 56.66 & 56.66 & 130.66 & 43 & 298.33 & 7.63 \\
\hline $3^{\text {rd }}$ month & 69 & 25 & 140 & 26.11 & 20.66 & 9.5 & 46.66 & 8 & 141.33 & 45 & 269.66 & 59.18 \\
\hline Avg & \begin{tabular}{|l|}
78.77 \\
\end{tabular} & 22.86 & 161 & 35 & 36.77 & 12.47 & 56.77 & 29.22 & 146.77 & 44.12 & 276.10 & 37.7 \\
\hline
\end{tabular}

Avg: Average; SD: Standart Deviation

Table 2. Number of live microorganisms in air samples collected from ICU at morning and evening in hospital 1, hospital 2 and hospital $3(\mathrm{n}=3)$.

\begin{tabular}{|c|c|c|c|c|c|c|c|c|c|c|c|c|}
\hline \multirow{3}{*}{ Samples } & \multicolumn{4}{|c|}{ Hospital 1 } & \multicolumn{4}{c|}{ Hospital 2 } & \multicolumn{4}{c|}{ Hospital 3 } \\
\cline { 2 - 15 } & \multicolumn{2}{|c|}{ Morning } & \multicolumn{2}{|c|}{ Evening } & \multicolumn{2}{c|}{ Morning } & \multicolumn{2}{c|}{ Evening } & \multicolumn{2}{c|}{ Morning } & \multicolumn{2}{c|}{ Evening } \\
\cline { 2 - 14 } & $\begin{array}{c}\text { Avg } \\
\left(\mathrm{cfu} / \mathrm{m}^{3}\right)\end{array}$ & SD & $\begin{array}{c}\text { Avg } \\
\left(\mathrm{cfu} / \mathrm{m}^{3}\right)\end{array}$ & SD & $\begin{array}{c}\text { Avg } \\
\left(\mathrm{cfu} / \mathrm{m}^{3}\right)\end{array}$ & SD & $\begin{array}{c}\text { Avg } \\
\left(\mathrm{cfu} / \mathrm{m}^{3}\right)\end{array}$ & SD & $\begin{array}{c}\text { Avg } \\
\left(\mathrm{cfu} / \mathrm{m}^{3}\right)\end{array}$ & SD & $\begin{array}{c}\text { Avg } \\
\left(\mathrm{cfu} / \mathrm{m}^{3}\right)\end{array}$ & SD \\
\hline $1^{\text {st }}$ month & 48.66 & 15.63 & 83 & 13.22 & 86 & 8.71 & 154 & 45.73 & 255 & 48.28 & 558.33 & 101.3 \\
\hline $2^{\text {nd }}$ month & 62.66 & 18 & 92.66 & 7.37 & 83.33 & 11.59 & 113.33 & 10.69 & 273 & 147.23 & 522 & 55.5 \\
\hline $3^{\text {rd }}$ month & 52 & 11.53 & 94.6 & 15.63 & 83 & 15.39 & 138 & 42 & 258 & 54 & 565.33 & 24.17 \\
\hline Avg & 54.44 & 15.05 & 90.10 & 12.07 & 84.11 & 11.89 & 135.11 & 32.8 & 262 & 83.17 & 548.53 & 60.32 \\
\hline
\end{tabular}

Avg: Average; SD: Standart Deviation 
Table 3. Number of live microorganisms in air samples collected from nursery section at morning and evening in hospital 1, hospital 2 and hospital $3(n=3)$.

\begin{tabular}{|c|c|c|c|c|c|c|c|c|c|c|c|c|}
\hline \multirow{4}{*}{ Samples } & \multicolumn{4}{|c|}{ Hospital 1 } & \multicolumn{4}{c|}{ Hospital 2 } & \multicolumn{4}{c|}{ Hospital 3 } \\
\cline { 2 - 14 } & \multicolumn{2}{|c|}{ Morning } & \multicolumn{2}{c|}{ Evening } & \multicolumn{2}{c|}{ Morning } & \multicolumn{2}{c|}{ Evening } & \multicolumn{2}{c|}{ Morning } & \multicolumn{2}{c|}{ Evening } \\
\cline { 2 - 13 } & $\begin{array}{c}\text { Avg } \\
\left(\mathrm{cfu} / \mathrm{m}^{3}\right)\end{array}$ & SD & $\begin{array}{c}\text { Avg } \\
\left(\mathrm{cfu} / \mathrm{m}^{3}\right)\end{array}$ & SD & $\begin{array}{c}\text { Avg } \\
\left(\mathrm{cfu} / \mathrm{m}^{3}\right)\end{array}$ & SD & $\begin{array}{c}\text { Avg } \\
\left(\mathrm{cfu} / \mathrm{m}^{3}\right)\end{array}$ & SD & $\begin{array}{c}\text { Avg } \\
\left(\mathrm{cfu} / \mathrm{m}^{3}\right)\end{array}$ & SD & $\begin{array}{c}\text { Avg } \\
\left(\mathrm{cfu} / \mathrm{m}^{3}\right)\end{array}$ & SD \\
\hline $1^{\text {st }}$ month & 38 & 24.63 & 84.66 & 13.86 & 48 & 20.22 & 63.66 & 14.57 & 152.33 & 42.89 & 283.66 & 62.93 \\
\hline $2^{\text {nd }}$ month & 32 & 12.76 & 65 & 10.58 & 36.66 & 11.5 & 95 & 13.22 & 106.33 & 24.7 & 211.33 & 20.74 \\
\hline $3^{\text {rd }}$ month & 49.66 & 10 & 87 & 20.42 & 51.66 & 10 & 83.33 & 16.25 & 145.66 & 61.77 & 186.33 & 45.5 \\
\hline Avg & 39.88 & 15.79 & 78.88 & 14.95 & 45.44 & 13.9 & 80.66 & 14.68 & 134.77 & 43.12 & 227.1 & 43.1 \\
\hline
\end{tabular}

Avg: Average; SD: Standart Deviation

\section{DISCUSSION}

Nosocomial infections have become known as one of the most important health issue nowadays. Nosocomial infections lead to increase human suffering and increase treatment cost. ${ }^{4}$ One study showed that death rate associated with HAIs has been elevated to several of top ten leading causes of death in U.S. ${ }^{15}$ It had been reported that HAI rate in pediatric oncology department of Aga Khan hospital, Karachi, Pakistan was 3.1 per 100 hospitalized patients. ${ }^{16}$ In Liaqat University hospital, Pakistan, the frequency of nosocomial infection was $29.13 \%$ in intensive care unit. ${ }^{17}$ These findings force us to redesign and improve preventive measures.

Microbial quality of the indoor air of different departments of hospital is one of the important factor related to nosocomial infections..$^{18}$ Dust arising from human movements such as sweeping or bed making in the hospitals may be a major offender of air borne contamination. ${ }^{19}$ Exposure of hospitalized patients to these air borne microorganisms often leads to infections, respiratory problems and allergic reactions. ${ }^{20}$ As the hospital environment is a source of acquired infections, knowledge of microbial flora of indoor air of various units of hospitals becomes mandatory to find out the possible causes of infections.

The present study aimed to get knowledge about the quality of indoor air of different departments of three hospitals. Number of microorganisms was counted, culture was studied to isolate the causative agents and a number of chemical tests were performed to confirm the bacterial species. In this study, only bacterial data was studied as bacteria play major role in spreading HAIs. ${ }^{10}$ For the selection criteria of hospital sections, it was kept in mind that one general ward (OPD) and two sensitive areas (ICU and nursery section) to check atmosphere microbial contamination. Sampling time was once early at morning just after disinfection process and the second time was at evening when sections were ex- 
posed a large number of individuals. So importance of air disinfection process was also evaluated.

It was found that the number of air borne microorganisms was significantly elevated in evening time air samples of three departments OPD (75.89\%), ICU (78.43\%) and nursery unit (81.5\%) in all three hospitals as shown in figure 1, 2 and 3 respectively. The number of microorganisms was less at morning time samples just air disinfection process. These findings showed the effectiveness of disinfection process in all three hospitals. However, the elevated number of colony forming units per cubic meter $\left(\mathrm{cfu} / \mathrm{m}^{3}\right)$ at evening time was due to some factors including the number of patients and visitors at wards during whole day. ${ }^{21}$

The frequency of microorganisms at morning/evening in OPD section of hospital $1(86.78 \pm 9.13 / 159.5 \pm 13.99)$, hospital $2(36.78 \pm 6.11 / 56.78 \pm 5.41)$ and hospital $3(146.8 \pm 13.93 / 273.8 \pm 14.72)$ fulfilled the criteria $300-400 \mathrm{cfu} / \mathrm{m}^{3}$ for patients wards. In ICU, number of microorganisms at morning time of hospital 1 (54.44 \pm 4.89$)$ met the standard criteria but hospital 2 (84.11 \pm 3.55$)$ and hospital 3 (262.0 \pm 27.49$)$ did not, while at evening time sampled air for hospital 1 (90.11 \pm 4.05), hospital $2(135.1 \pm 12.05)$ and hospital $3(548.6 \pm 20.78)$ could not confirm to permitted range of microbes. As nursery sections are also considered as first-class environments according to DIN 1946/4 standards, allowed number of microbes for nursery is $<70 \mathrm{CFU} / \mathrm{m}^{3}$ as in case of ICU. The number of microorganisms in hospital 1(39.89 \pm 5.561$)$ and hospital 2 (45.44 \pm 4.79$)$ suited to criteria in samples taken at morning just after disinfection process but hospital $3(134.8 \pm 15.02)$ did not in nursery section. The quality of air sampled at evening in hospital 1 (78.89 \pm 5.675$)$, hospital 2 (80.67 \pm 6.24$)$ and hospital 3 $(228.1 \pm 25.86)$ did not adhere to requirements. ${ }^{22}$ Absence of unidirectional flow system in different sections of all three hospitals might be a major factor for such a rise microbial count. Moreover, disinfection process done at morning time was not performed at evening time in three hospitals. Among three hospitals, hospital 3 had much increased number of viable microorganisms in OPD, ICU and nursery sections as compared to hospital 1 and hospital 2. As the hospital 3 was a teaching hospital, more number of individuals visited it. Movements associated with high number of visitors increased the atmospheric microbial density.

Chemical tests performed to identify microorganisms in this study showed the presence of E. coli, S. aureus, P. aeruginosa and K. pneumonia. E. coli is an emerging nosocomial pathogen in health care system and can cause urinary tract infection, pneumonia, septicemia and gastroenteritis. ${ }^{23,24}$ S. aureus is the most notorious pathogen for nosocomial infections and can cause diseases in immunocompromised hospitalized patients. ${ }^{25} \mathrm{~A}$ study showed that $P$. aeruginosa is responsible 
for $11 \%$ of all nosocomial infections and may cause surgical and wound infections, pneumonia, cystic fibrosis and bacteremia. ${ }^{26} \mathrm{~K}$. pneumonia, the eighth significant pathogen in healthcare settings, may be involved in neonatal septicemia, pneumonia, wound infections and septicemia. ${ }^{27}$ Presence of nosocomial infections associated pathogens in the atmospheric environment of three hospitals imply a great risk for hospitalized patients at Pakistan. Proper control measures become mandatory to reduce air borne microorganism's count. Guidance for implying and maintaining high hygiene environment at hospital levels should be encouraged.

The outcome of present study was that microbe contaminated air might be a source of nosocomial infection in hospital environments at Pakistan. Our studies showed that quality of atmospheres of three hospitals varies depending upon the number of individuals visiting hospitals. Systematic vigilance, disinfection process updating, infection control practices among health care workers and limitation of patients relative might be the best strategies to keep hospitals environment at safe level. Further studies are necessary to reveal the risk factors associated with nosocomial infections at developing countries so that adequate measures can be taken to reduce the mortality among these patients.

\section{CONFLICT OF INTEREST STATEMENT}

We declare that we have no conflict of interest.

\section{ACKNOWLEDGEMENTS}

The authors are grateful to Mr.Mehar Ishfaq, director of Medisave Pharmaceuticals, Lahore for the samples being tested and analyzed there.

\section{REFERENCES}

1. Dancer, S. J. The role of environmental cleaning in the control of hospital-acquired infection. Journal of Hospital Infection 73, 378-385 (2009).

2. Of, P. Prevention and Control of. Forestry 49, 259-270 (2002).

3. Curtis, L. T. Prevention of hospital-acquired infections: review of non-pharmacological interventions. Journal of Hospital Infection 69, 204-219 (2008).

4. McFee, R. B. Nosocomial or Hospital-acquired Infections: An Overview. Disease-a-Month 55, 422-438 (2009).

5. Klevens, R. M. et al. Estimating health care-associated infections and deaths in U.S. hospitals, 2002. Public Health Rep 122, 160-166 (2007).

6. Klavs, I. et al. Prevalance of and risk factors for hospital-acquired infections in Sloveniaresults of the first national survey, 2001. The Journal of hospital infection 54, 149-57 (2003).

7. Starakis, I., Marangos, M., Gikas, A., Pediaditis, I. \& Bassaris, H. Repeated point prevalence survey of nosocomial infections in a Greek University hospital. Journal of Chemotherapy 14, 272-278 (2002). 
8. Emori, T. G. \& Gaynes, R. P. An overview of nosocomial infections, including the role of the microbiology laboratory. Clinical Microbiology Reviews 6, 428-442 (1993).

9. Lam, B. C. C., Lee, J. \& Lau, Y. L. Hand Hygiene Practices in a Neonatal Intensive Care Unit: A Multimodal Intervention and Impact on Nosocomial Infection. Pediatrics 114, e565-e571 (2004).

10. Gatermann S et al. [MIQ 02: Urinary Tract Infections: Quality standards for microbiological infections]. Munchen: Urban \& Fischer 8-21 (2005).

11. Horan, T. C., Andrus, M. \& Dudeck, M. A. CDC/NHSN surveillance definition of health care-associated infection and criteria for specific types of infections in the acute care setting. American Journal of Infection Control 36, 309-332 (2008).

12. Mussi-Pinhata, M. M. \& Do Nascimento, S. D. Neonatal nosocomial infections. [Portuguese $\backslash$ rInfecoes neonatais hospitalares. Jornal de Pediatria 77, S81-S96 (2001).

13. Scheckler, W. E. et al. Requirements for infrastructure and essential activities of infection control and epidemiology in hospitals: a consensus panel report. Society for Healthcare Epidemiology of America. Infection control and hospital epidemiology : the official journal of the Society of Hospital Epidemiologists of America 19, 114-124 (1998).

14. Bergey, D. H., Breed, R. S., Murray, E. G. . \& Smith, N. R. Bergey's Manual of Determinative Bacteriology. Lippincott Williams \& Wilkins. 1094 (1957). doi:10.2307/1218353

15. Kung, H., Ph, D., Hoyert, D. L., Ph, D. \& Xu, J. Deaths : Final Data for 2005. 56, (2008).

16. Siddiqui, N., Wali, R., Haque, A. \& Fadoo, Z. Original Article Healthcare-associated infections among pediatric oncology patients in Pakistan : risk factors and outcome. J Infect Dev Ctries 5, 416-421 (2012).

17. Shaikh, J. M., Devrajani, B. R., Shah, S. Z., Akhund, T. \& Bibi, I. Frequency, pattern and etiology of nosocomial infection in intensive care unit: an experience at a tertiary care hospital. $J$ Ayub Med Coll Abbottabad 2o, 37-40 (2008).

18. Ekhaise, F. O., Isitor, E. E., Idehen, O. \& Emoghene, a O. Airborne Microflora in the Atmosphere of an Hospital Environment of University of Benin Teaching Hospital ( UBTH ), Benin City , Nigeria. City 6, 166-170 (2010).

19. Haley, R. W., Culver, D. H., White, J. W., Morgan, W. M. \& Emori, T. G. The nationwide nosocomial infection rate. A new need for vital statistics. American journal of epidemiology 121, 159-67 (1985).

20. Raka, A. L. et al. Prevalence of Nosocomial Infections in High - Risk Units in the University Clinical Center of Kosova Published by : Cambridge University Press on behalf of The Society for Healthcare Epidemiology of America Stable URL : http://www.jstor.org/stable/10.1086. 2-5 (2017).

21. Çakir, N. A., Uçar, F. B., Uztan, A. H., Çorbaci, C. \& Akpinar, O. Determination and comparison of microbial loads in atmospheres of two hospitals in Izmir, Turkey. Annals of Agricultural and Environmental Medicine 2o, 106-110 (2013).

22. Club, B. Bacteriological monitoring in a burns centre. 7, 1-5 (2017).

23. Lausch, K. R., Fuursted, K., Larsen, C. S. \& Storgaard, M. Colonisation with multi-resistant Enterobacteriaceae in hospitalised Danish patients with a history of recent travel: A cross-sectional study. Travel Medicine and Infectious Disease 11, 320-323 (2013). 
24. Zhao, W., Yang, S., Huang, Q. \& Cai, P. Bacterial cell surface properties: Role of loosely bound extracellular polymeric substances (LB-EPS). Colloids and Surfaces B: Biointerfaces 128, 600-607 (2015).

25. Laham, N. Al et al. MRSA clonal complex 22 strains harboring toxic shock syndrome toxin (TSST-1) are endemic in the primary hospital in Gaza, Palestine. PLoS ONE 10, 1-17 (2015).

26. Bălăşoiu, M., Bălăşoiu, A. T., Mănescu, R., Avramescu, C. \& Ionete, O. Pseudomonas aeruginosa resistance phenotypes and phenotypic highlighting methods. Current health sciences journal 40, 85-92 (2014).

27. Lin, Y. T., Wang, Y. P., Wang, F. Der \& Fung, C. P. Community-onset Klebsiella pneumoniae pneumonia in Taiwan: Clinical features of the disease and associated microbiological characteristics of isolates from pneumonia and nasopharynx. Frontiers in Microbiology 6, 1-8 (2015).

(Received 23 March 2017; accepted 11 April 2017) 